\title{
Cerebral venous drainage in patients with dural arteriovenous fistulas: correlation with clinical presentation
}

\author{
João Ferreira de Melo Neto, MD, ${ }^{1}$ Eduardo E. Pelinca da Costa, MD, ${ }^{1}$ Nilson Pinheiro Junior, MD, ${ }^{1}$ \\ André L. Batista, MD, ${ }^{1}$ Georges Rodesch, MD, PhD, ${ }^{2}$ Serge Bracard, MD, ${ }^{3}$ and \\ Antônio G. Oliveira, MD, PhD 4
}

'Department of Neurosurgery, Hospital Universitário Onofre Lopes, Universidade Federal do Rio Grande do Norte, Natal/RN, Brazil; '2Department of Diagnostic and Interventional Neuroradiology, Hôpital Foch, Suresnes, France; ${ }^{3}$ Department of Diagnostic and Interventional Neuroradiology, Université de Lorraine, Inserm, IADI, CHRU Nancy, France; and 'Department of Pharmacy, Centro de Ciências da Saúde, Universidade Federal do Rio Grande do Norte, Natal/RN, Brazil

OBJECTIVE Dural arteriovenous fistulas (DAVFs) are abnormal, acquired arteriovenous connections within the dural leaflets. Their associated symptoms may be mild or severe and are related to the patient's venous anatomy. With the hypothesis that the patient's venous anatomy determines the development of symptoms, the authors aimed to identify which venous anatomy elements are important in the development of major symptoms in patients with a DAVF.

METHODS A multicenter study was performed based on the retrospective analysis of cerebral angiographies with systematic assessment of brain drainage pathways (including fistula drainage) in patients over 18 years of age with a single DAVF. The patients were divided into two groups: those with minor (group 1, $n=112$ ) and those with major (group 2, $n=$ 89) symptoms. Group 2 was subdivided into two groups: patients with hemorrhage (group $2 a, n=47$ ) and patients with severe nonhemorrhagic symptoms (group $2 b, n=42$ ).

RESULTS The prevalence of stenosis in DAVF venous drainage and the identification of tiny anastomoses between venous territories were significantly higher in group 2 (32.6\% and $19.1 \%$, respectively) compared with group $1(2.68 \%$ and $5.36 \%$, respectively). Stenosis of DAVF venous drainage was significantly more frequent in group $2 a$ than in group $2 \mathrm{~b}(51.1 \%$ vs $11.9 \%, \mathrm{p}<0.001)$. Group $2 \mathrm{~b}$ patients had increased prevalence of shared use of the cerebral main drainage pathway $(85.0 \%$ vs $53.2 \%, p=0.002)$, the absence of an alternative route $(45.0 \%$ vs $17.0 \%, p=0.004)$, and the presence of contrast stagnation ( $62.5 \%$ vs $29.8 \%, p=0.002$ ) compared with group 2a patients. In patients with high-grade fistulas, the group with major symptoms had increased prevalence of a single draining direction $(31.3 \%$ vs $8.33 \%, p=$ $0.003)$, stenosis in the draining vein $(35.0 \%$ vs $6.25 \%, p=0.000)$, the absence of an alternative pathway for brain drainage $(31.3 \%$ vs $12.5 \%, p=0.017)$, and the presence of contrast stagnation $(48.8 \%$ vs $22.9 \%, p=0.004)$.

CONCLUSIONS Major symptoms were observed when normal brain tissue venous drainage was impaired by competition with DAVF (predominance in group $2 b$ ) or when DAVF venous drainage had anatomical characteristics that hindered drainage, with consequent venous hypertension on the venous side of the DAVF (predominance in group 2a). The same findings were observed when comparing two groups of patients with high-grade lesions: those with major versus those with minor symptoms.

https://thejns.org/doi/abs/10.3171/2020.6.JNS20922

KEYWORDS cortical venous drainage; clinical presentation; dural arteriovenous fistula; vascular disorders

$\mathrm{D}$ URAL arteriovenous fistulas (DAVFs) are acquired lesions involving primarily dural arteries and dural venous sinuses or lakes, with or without reflux into the pial veins. These are rare conditions, comprising about $10 \%$ to $15 \%$ of all intracranial arteriovenous shunts.
Some DAVFs pursue an aggressive course and are characterized by the presence of cerebral venous reflux. Their treatment is targeted toward complete elimination of the shunt. DAVFs that do not have cerebral venous reflux usually have a benign course, and treatment may be conser-

ABBREVIATIONS DAVF = dural arteriovenous fistula.

SUBMITTED April 14, 2020. ACCEPTED June 16, 2020.

INCLUDE WHEN CITING Published online November 13, 2020; DOI: 10.3171/2020.6.JNS20922. 
vative if symptoms are well tolerated. The prognosis depends on the relationship between the DAVF and the brain venous circulation. ${ }^{1-7}$

Some authors have reported that the initiating event in DAVF pathogenesis may be localized venous hypertension leading to the production of vascular endothelial growth factor and inducing angiogenesis. ${ }^{1-3}$ Other authors reported that the initiating event is a venous thrombosis that opens preexisting arteriovenous connections, causing the development of the DAVF. ${ }^{1,4}$ As some authors have noted, those theories are not mutually exclusive..$^{5-7}$ In addition, an association has been reported between clinical conditions that induce hypercoagulability and DAVFbearing patients..$^{8-10}$

Because the disease prognosis in DAVF is directly related to the anatomy of venous drainage, the most widely used classification systems, described by Borden et al. ${ }^{11}$ and Cognard et al., ${ }^{12}$ are based on the venous drainage pattern of the lesion. ${ }^{13-15}$ Other radiological aspects related to venous drainage are also associated with high risk, such as pseudophlebitis, ${ }^{16-18}$ distant venous sinus location, ${ }^{19}$ single drainage, and venous thrombosis. ${ }^{18,20}$ The clinical finding most consistent with an aggressive course is initial presentation with hemorrhage..$^{21,22}$ Most DAVFs tend to remain clinically stable,,$^{15,23,24}$ with progression to more aggressive lesions occurring in $2 \%$ to $16.1 \%$ of cases. ${ }^{24,25}$ On the other hand, high-grade lesions have a $15 \%$ to $19.2 \%$ annual incidence rate of neurological or hemorrhagic episodes. ${ }^{26,27}$

Symptoms may be directly related to the DAVF (e.g., hemorrhage) or to the impact of the fistula on brain tissue (e.g., dementia, extrapyramidal syndrome, focal neurological deficits, and epilepsy). In clinical practice, cases are seen in which symptoms apparently result from an association between the patient's DAVF and insufficiency of the patient's venous system..$^{20,28,29}$ In the literature, studies on this topic have been limited to review of the venous drainage of DAVF, and we did not find any papers evaluating the association between unfavorable venous configuration at the time of clinical presentation and the incidence of severe symptoms.

Because of the limited number of studies that focus on the effects of venous insufficiency in DAVF patients, the aim of this study was to systematically assess patient brain drainage pathways (including fistula drainage) while seeking to identify variables that quantify the importance of venous anatomy as an additional restrictive factor for parenchymal drainage, increasing the likelihood of symptoms.

\section{Methods}

In this multicenter retrospective study, we analyzed all cerebral angiographies performed in DAVF patients between 2006 and 2016 at the Onofre Lopes University Hospital (Natal, Brazil), University Hospital of Nancy (Nancy, France), and Foch Hospital (Suresnes, France). Inclusion criteria were age over 18 years with a single-site dural fistula. At each study center, the patient data were available in the PACS in DICOM format. Each angiography was reviewed by two experienced interventional neuroradiologists (E.E.P.C., with 18 years' experience, and J.F.M.N., with 16 years' experience). Age, sex, DAVF location, and Borden and Cognard classification scores were recorded. The study was approved by the institution's Research Ethics Committee, which waived written informed consent because the study was retrospective.

Initial clinical presentation was classified into mild symptoms (cranial nerve deficit, bruit, tinnitus, headache, dizziness, and orbital symptoms) and severe symptoms (hemorrhage, venous infarction, neurological deficit, intracranial hypertension, epilepsy, and visual symptoms). The patients were divided into two groups according to the presenting symptoms: group 1, minor symptoms (patients with mild symptoms or asymptomatic), and group 2, major symptoms (patients with hemorrhage or severe symptoms). The patients from group 2 were further divided into group $2 \mathrm{a}$ (patients with hemorrhage) and group $2 \mathrm{~b}$ (patients with severe nonhemorrhagic neurological symptoms) with the purpose of comparing variables of restricted venous drainage between the subgroups with major symptoms.

Lesions were considered as high grade when classified as Cognard types 2B to 5 and Borden types 2 and 3 . Patients with high-grade lesions were divided into a group with minor symptoms and another with major symptoms, with the purpose of comparing variables of restricted venous drainage.

\section{Study Variables}

The study of the venous system consisted of the identification and classification of the following venous elements as complete, incomplete, or absent: the superficial middle cerebral vein, basal vein, and lateral tentorial sinus and the anastomotic veins in supratentorial lesions (Fig. 1 ); and the venous confluence of the great cerebral vein, inferior vermian, superior cerebellar confluents, and petrosal vein in the posterior fossa, and the lateral mesencephalic vein (Fig. 2). Dural venous sinuses were identified and described as normal, stenotic, or occluded.

Three variables were studied for the evaluation of restriction to the cerebral circulation: fistula competition for the brain's main drainage pathway, existence of an alternative efficient venous drainage pathway for the brain tissue, and presence of contrast stagnation. For supratentorial lesions, three drainage pathways were considered: anterior to the cavernous sinus and pterygoid plexus, superior to the superior sagittal sinus, and posteroinferior to the transverse sinus. For the infratentorial lesions, we considered the anterior pathway by the petrosal vein and superior petrosal sinus, the superior pathway by the great cerebral vein, and the posterior pathway by the medial tentorial sinus.

With regard to DAVF angioarchitecture, the location, drainage direction in the affected venous sinus, and presence of cortical venous drainage were identified. We also looked for venous thrombosis, venous ectasia, and a pseudophlebitic pattern. The DAVF was analyzed for factors that could potentially cause restriction, including occlusion or stenosis of the veins and venous sinuses involved in the drainage of the fistula. The pattern of venous anastomosis when the drainage involved more than one territory was also identified. The anastomotic pattern was considered good when all of the connections between territories were regular, ensuring adequate flow. Fine and tortuous, 


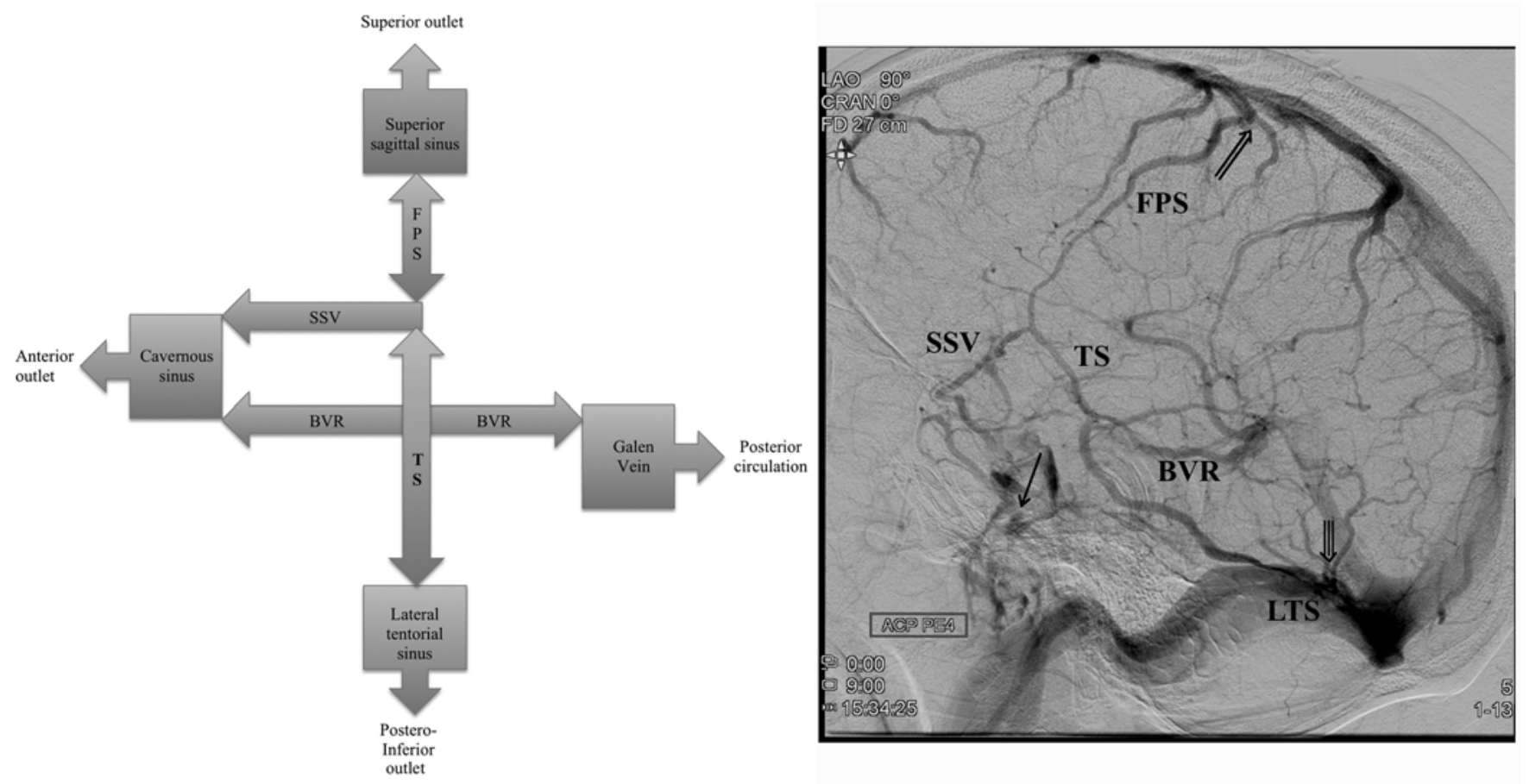

FIG. 1. Venous connections in anterior circulation, as depicted in a diagram (left) and in left carotid angiography (right; single arrow, anterior outlet; double arrow, superior outlet; triple arrow, posterior-inferior outlet). BVR = basal vein of Rosenthal; FPS = fronto-parieto-sylvian anastomosis; LTS = lateral tentorial sinus; SSV = superficial sylvian vein; TS = temporo-sylvian anastomosis.

and usually multiple, venous channels that were not effective in ensuring proper venous flow were classified as "tiny."

Although all patients underwent a complete venous system evaluation, for the purpose of statistical analysis, supratentorial DAVFs were grouped separately from their infratentorial counterparts.

\section{Statistical Methods}

A target sample size of 200 patients was defined, which would afford $80 \%$ statistical power to detect differences in study variables with odds ratios greater than 3.0 between the groups with major and minor symptoms, with a prevalence greater than $10 \%$ in one group, assuming approximately equal-sized groups.

Intergroup proportions were compared using the chisquare test or Fisher exact test when cell sizes were small. All tests were two-tailed and differences were considered significant when $\mathrm{p}$ values were $<0.05$. Stata 15 (Stata Corp.) was used for statistical analysis.
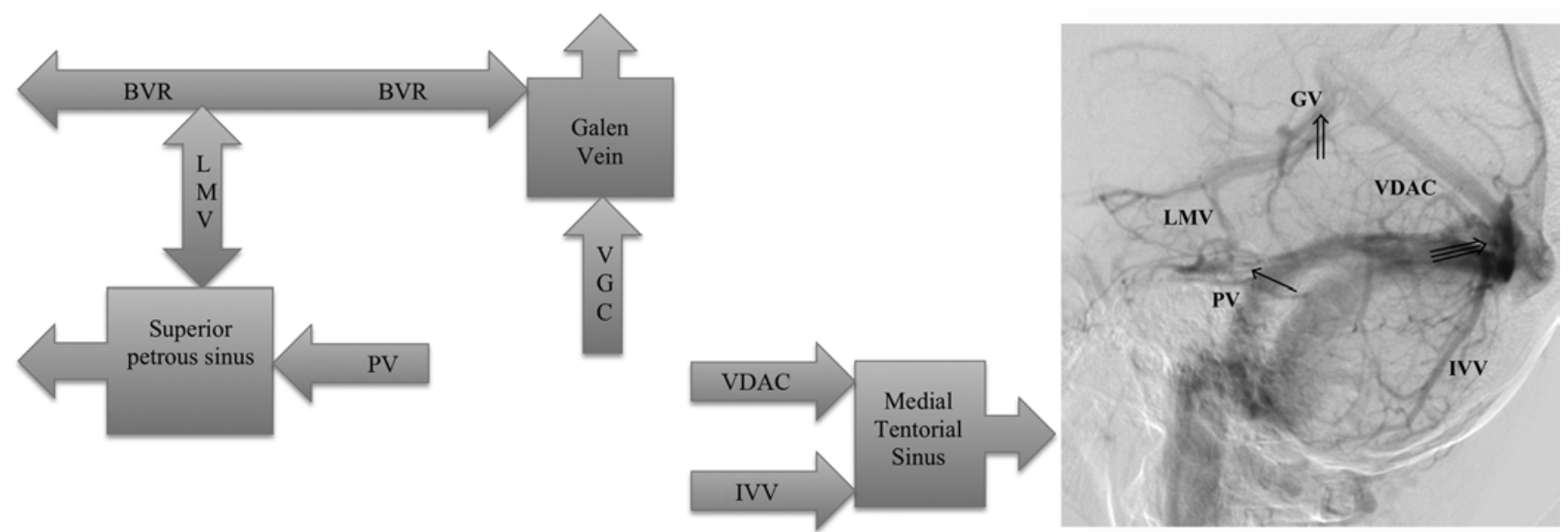

FIG. 2. Venous connections in the posterior circulation as depicted in a diagram (left) and in left vertebral angiography (right; single arrow, anterior outlet; double arrow, superior outlet; triple arrow, posterior outlet). GV = Galen vein; IVV = inferior vermian vein; LMV = lateral pontomesencephalic vein; $P V=$ petrous vein; VDAC = veins from dorsal aspect of cerebellum; VGC = vein of Galen confluent. 
TABLE 1. Characteristics of the study population of DAVF patients with minor (group 1) and major (group 2) symptoms

\begin{tabular}{|c|c|c|c|}
\hline \multirow[b]{2}{*}{ Variables } & \multicolumn{2}{|c|}{ Symptoms } & \multirow[b]{2}{*}{$\begin{array}{c}p \\
\text { Value }\end{array}$} \\
\hline & $\begin{array}{c}\text { Minor } \\
\text { (group 1: } n=112 \text { ) }\end{array}$ & $\begin{array}{c}\text { Major } \\
\text { (group 2: } \mathrm{n}=89 \text { ) }\end{array}$ & \\
\hline $\begin{array}{l}\text { Age in yrs, } \\
\text { mean } \pm \text { SD }\end{array}$ & $59.2 \pm 14.0$ & $59.9 \pm 13.5$ & 0.73 \\
\hline Male & $50(44.6 \%)$ & $72(80.9 \%)$ & $<0.001$ \\
\hline \multicolumn{4}{|l|}{$\begin{array}{l}\text { DAVF } \\
\text { classification }\end{array}$} \\
\hline Borden type & & & $<0.001$ \\
\hline 1 & $64(57.1 \%)$ & $9(10.1 \%)$ & \\
\hline 2 & $17(15.2 \%)$ & $12(13.5 \%)$ & \\
\hline 3 & $31(27.7 \%)$ & $69(76.4 \%)$ & \\
\hline Cognard type & & & $<0.001$ \\
\hline 1 & $46(41.1 \%)$ & $8(8.99 \%)$ & \\
\hline $2 A$ & $17(15.2 \%)$ & $1(1.12 \%)$ & \\
\hline $2 A B$ & $17(15.2 \%)$ & $15(16.8 \%)$ & \\
\hline 3 & $23(20.5 \%)$ & $28(31.5 \%)$ & \\
\hline 4 & $9(8.00 \%)$ & $32(36.0 \%)$ & \\
\hline 5 & $0(0.0 \%)$ & $5(5.62 \%)$ & \\
\hline $\begin{array}{l}\text { Cortical venous } \\
\text { drainage }\end{array}$ & $48(38.5 \%)$ & $81(89.9 \%)$ & $<0.001$ \\
\hline Venous ectasias & $10(8.93 \%)$ & $37(41.6 \%)$ & $<0.001$ \\
\hline Pseudophlebitis & $16(14.3 \%)$ & 33 (37.1\%) & $<0.001$ \\
\hline Thrombosis & $36(32.1 \%)$ & 35 (39.3\%) & 0.29 \\
\hline
\end{tabular}

Values are presented as number (\%) of patients unless otherwise indicated.

\section{Results}

The study population consisted of 201 patients, divided into two groups: 112 with minor symptoms (group 1) and 89 with major symptoms (group 2). The percentages of male patients in the two groups were $44.6 \%(\mathrm{n}=50)$ and $80.9 \%(\mathrm{n}=72)$, respectively $(\mathrm{p}<0.001)$. In Borden's classification, most patients with minor symptoms had type 1 DAVF $(n=64,57.1 \%)$, while most with major symptoms had type 3 DAVF $(n=69,76.4 \%)(p<0.001)$. A similar result was found with the Cognard classification $(\mathrm{p}<$ 0.001). Table 1 shows the patient characteristics of both groups.

The prevalences of cortical venous drainage, venous ectasias, and a pseudophlebitic pattern were significantly higher $(\mathrm{p}<0.001)$ in the group of patients with major symptoms. No statistical difference in the prevalence of venous sinus thrombosis was found $(\mathrm{p}=0.29)$ (Table 1$)$.

\section{Study of Venous System Anatomy}

The analysis of the studied venous confluents is described in Table 2. For both supratentorial and infratentorial lesions, we observed that their partial or complete absence of venous confluents was not significantly associated with the occurrence of major symptoms.

When the patient's venous disposition was assessed for residual drainage capacity, statistical differences were
TABLE 2. Venous element analysis in DAVF patients with minor (group 1) and major (group 2) symptoms

\begin{tabular}{|c|c|c|c|}
\hline \multirow[b]{2}{*}{ Venous Element } & \multicolumn{2}{|c|}{ Symptoms } & \multirow[b]{2}{*}{$\begin{array}{c}\mathrm{p} \\
\text { Value }\end{array}$} \\
\hline & $\begin{array}{c}\text { Minor } \\
\text { (group 1: } \\
n=112 \text { ) }\end{array}$ & $\begin{array}{c}\text { Major } \\
\text { (group 2: } \\
n=89 \text { ) }\end{array}$ & \\
\hline \multicolumn{4}{|l|}{ Anterior circulation } \\
\hline Superficial middle cerebral vein & & & 0.13 \\
\hline Complete & $69(69.0 \%)$ & $40(54.1 \%)$ & \\
\hline Incomplete & $24(24.0 \%)$ & $27(36.5 \%)$ & \\
\hline Absent & $7(7.00 \%)$ & $7(9.46 \%)$ & \\
\hline Basal vein of Rosenthal & & & 0.95 \\
\hline Complete & $71(71.0 \%)$ & $51(68.9 \%)$ & \\
\hline Incomplete & $21(21.0 \%)$ & $17(23.0 \%)$ & \\
\hline Absent & $8(8.00 \%)$ & $6(8.11 \%)$ & \\
\hline Lateral tentorial sinus & & & 0.17 \\
\hline Present & $81(81.0 \%)$ & $51(68.9 \%)$ & \\
\hline Absent & $3(3 \%)$ & $5(6.76 \%)$ & \\
\hline Retrograde & $16(16.0 \%)$ & $18(24.3 \%)$ & \\
\hline $\begin{array}{l}\text { Anastomoses btwn cortical ter- } \\
\text { ritories }\end{array}$ & & & 0.82 \\
\hline FPS + TS & $55(55.0 \%)$ & $40(54.1 \%)$ & \\
\hline FPS or TS & $26(26.0 \%)$ & $22(29.7 \%)$ & \\
\hline Absent & $19(19.0 \%)$ & $12(16.2 \%)$ & \\
\hline \multicolumn{4}{|l|}{$\begin{array}{l}\text { Posterior circulation confluents and } \\
\text { anastomotic veins }\end{array}$} \\
\hline Cerebellar drainage to Galen vein & $15(83.3 \%)$ & $18(100 \%)$ & 0.23 \\
\hline Inferior vermian vein & $17(94.4 \%)$ & $13(72.2 \%)$ & 0.18 \\
\hline Tentorial medial sinus & $18(100 \%)$ & $13(72.2 \%)$ & 0.05 \\
\hline Petrosal vein & $17(94.4 \%)$ & $15(83.3 \%)$ & 0.60 \\
\hline Lateral mesencephalic vein & $12(66.7 \%)$ & $12(66.7 \%)$ & $>0.99$ \\
\hline
\end{tabular}

FPS = fronto-parieto-sylvian; TS = temporo-sylvian .

Values are presented as number (\%) of patients.

found. Table 3 shows that the fistula used the brain's main venous drainage pathway in $37(33.0 \%)$ patients with minor symptoms and in $59(66.3 \%)$ patients with major symptoms $(p<0.001)$. There were no alternative brain drainage pathways in $6(5.36 \%)$ patients with minor symptoms or in $26(29.2 \%)$ patients with major symptoms ( $\mathrm{p}<$ $0.001)$. Contrast stagnation in brain parenchyma was observed in $11(9.91 \%)$ patients with minor symptoms and in $39(43.8 \%)$ patients with major symptoms ( $\mathrm{p}<0.001)$.

\section{Study of DAVF Venous Drainage}

Table 3 displays the analysis of the variables related to restriction of DAVF circulation. Stenosis or occlusion of draining veins was present in $5(4.5 \%)$ patients with minor symptoms and in 31 (34.8\%) patients with major symptoms ( $\mathrm{p}<0.001)$. Stenosis or occlusion of the DAVF drainage venous sinus was found in $38(33.9 \%)$ patients with minor symptoms and in $40(44.9 \%)$ patients with major symptoms $(p=0.03)$. The presence of tiny or mixed anastomoses between venous territories was identified in 19 
TABLE 3. Venous drainage impairment in DAVF patients with minor (group 1) and major (group 2) symptoms

\begin{tabular}{|c|c|c|c|}
\hline \multirow[b]{2}{*}{ Drainage } & \multicolumn{2}{|c|}{ Symptoms } & \multirow[b]{2}{*}{$\begin{array}{c}p \\
\text { Value }\end{array}$} \\
\hline & $\begin{array}{c}\text { Minor } \\
\text { (group 1: } n=112 \text { ) }\end{array}$ & $\begin{array}{c}\text { Major } \\
\text { (group 2: } \mathrm{n}=89 \text { ) }\end{array}$ & \\
\hline \multicolumn{4}{|l|}{ Fistula drainage } \\
\hline $\begin{array}{l}\text { Sinus drainage } \\
\text { condition }\end{array}$ & & & 0.030 \\
\hline Normal & $74(66.1 \%)$ & $49(55.1 \%)$ & \\
\hline Stenosis & $8(7.14 \%)$ & $2(2.25 \%)$ & \\
\hline Occlusion & $30(26.8 \%)$ & $38(42.7 \%)$ & \\
\hline $\begin{array}{l}\text { Cortical draining } \\
\text { veins }\end{array}$ & & & $<0.001$ \\
\hline Normal & $48(42.9 \%)$ & $51(57.3 \%)$ & \\
\hline Stenosis & $3(2.68 \%)$ & $29(32.6 \%)$ & \\
\hline Occlusion & $2(1.79 \%)$ & $2(2.25 \%)$ & \\
\hline Absence & $59(52.7 \%)$ & $7(7.87 \%)$ & \\
\hline $\begin{array}{l}\text { No. of draining } \\
\text { veins }\end{array}$ & & & 0.84 \\
\hline Single & $38(33.9 \%)$ & $29(32.6 \%)$ & \\
\hline Multiple & $74(66.1 \%)$ & $60(67.4 \%)$ & \\
\hline Anastomosis type & & & $<0.001$ \\
\hline Good & $32(28.6 \%)$ & $44(49.4 \%)$ & \\
\hline Mixed & $13(11.6 \%)$ & $20(22.5 \%)$ & \\
\hline Tiny & $6(5.36 \%)$ & $17(19.1 \%)$ & \\
\hline None & $61(54.5 \%)$ & $8(9 \%)$ & \\
\hline \multicolumn{4}{|l|}{ Cerebral drainage } \\
\hline $\begin{array}{l}\text { Shared use of main } \\
\text { pathway }\end{array}$ & $37(41.6 \%)$ & $60(68.2 \%)$ & $<0.001$ \\
\hline $\begin{array}{l}\text { Absence of alterna- } \\
\text { tive pathway }\end{array}$ & $6(6.74 \%)$ & $27(30.7 \%)$ & $<0.001$ \\
\hline $\begin{array}{l}\text { Presence of con- } \\
\text { trast stagnation }\end{array}$ & $11(12.4 \%)$ & $39(44.3 \%)$ & $<0.001$ \\
\hline
\end{tabular}

Values are presented as number (\%) of patients.

(17\%) patients with minor symptoms and in $37(41.6 \%)$ patients with major symptoms ( $\mathrm{p}<0.001)$. The presence of a single draining vein was found in 38 (33.9\%) patients with minor symptoms and in 29 (32.6\%) patients with major symptoms $(\mathrm{p}=0.840)$.

\section{Dural Cavernous Fistulas}

Dural cavernous fistulas were found in 29 patients. Twenty-four (82.8\%) patients had minor symptoms and 5 (17.2\%) patients had a major symptom (blindness). Seven (24.1\%) patients had cortical venous drainage, with none of these patients having brain hemorrhage or neurological deficits other than those related to the optic nerve and eye movements.

\section{Low-Grade DAVF and Aggressive Evolution}

Nine patients with low-grade DAVF were found to have major symptoms, 7 with neurological deficits and 2 with hemorrhage. In 4 patients, the DAVF was located in the
TABLE 4. Restricted venous drainage in patients with DAVF and major symptoms: comparison between patients with hemorrhage (group 2a) and neurological deficit (group 2b)

\begin{tabular}{|c|c|c|c|}
\hline Drainage & $\begin{array}{c}\text { Hemorrhage } \\
\text { (group 2a: } n=47 \text { ) }\end{array}$ & $\begin{array}{l}\text { Neurological Deficit } \\
\text { (group 2b: } n=42 \text { ) }\end{array}$ & $\begin{array}{c}p \\
\text { Value }\end{array}$ \\
\hline \multicolumn{4}{|l|}{ Fistula drainage } \\
\hline $\begin{array}{l}\text { Sinus drainage } \\
\text { condition }\end{array}$ & & & 0.009 \\
\hline Normal & $32(60.1 \%)$ & $17(40.5 \%)$ & \\
\hline Stenosis & $0(0.00 \%)$ & $2(4.76 \%)$ & \\
\hline Occlusion & $15(31.9 \%)$ & $23(54.8 \%)$ & \\
\hline $\begin{array}{l}\text { Cortical draining } \\
\text { veins }\end{array}$ & & & $<0.001$ \\
\hline Normal & $19(40.1 \%)$ & $32(76.2 \%)$ & \\
\hline Stenosis & $24(51.1 \%)$ & $5(11.9 \%)$ & \\
\hline Occlusion & $2(4.26 \%)$ & $0(0.00 \%)$ & \\
\hline Absence & $2(4.26 \%)$ & $5(11.9 \%)$ & \\
\hline $\begin{array}{l}\text { No. of draining } \\
\text { veins }\end{array}$ & & & 0.010 \\
\hline Single & $26(55.3 \%)$ & $34(81.0 \%)$ & \\
\hline Multiple & $21(44.7 \%)$ & $8(19.1 \%)$ & \\
\hline $\begin{array}{l}\text { Anastomosis } \\
\text { type }\end{array}$ & & & 0.68 \\
\hline Good & $23(28.6 \%)$ & $21(58.3 \%)$ & \\
\hline Mixed & $11(11.6 \%)$ & $9(25.0 \%)$ & \\
\hline Tiny & $11(5.40 \%)$ & $6(16.7 \%)$ & \\
\hline \multicolumn{4}{|l|}{ Cerebral drainage } \\
\hline $\begin{array}{l}\text { Shared use of } \\
\text { main pathway }\end{array}$ & $25(53.2 \%)$ & $34(85.0 \%)$ & 0.002 \\
\hline $\begin{array}{l}\text { Absence of alter- } \\
\text { native pathway }\end{array}$ & $8(17.0 \%)$ & $18(45.0 \%)$ & 0.004 \\
\hline $\begin{array}{l}\text { Presence of con- } \\
\text { trast stagnation }\end{array}$ & $14(29.8 \%)$ & $25(62.5 \%)$ & 0.002 \\
\hline
\end{tabular}

Values are presented as number (\%) of patients.

transverse and sigmoid sinuses, 2 had torcular lesions, and 3 had dural cavernous fistulas. These patients had DAVF associated with restrictions to the drainage. The fistula drained through the main venous outlet in 5 patients out of 6 noncavernous fistulas. Two cavernous fistula patients had partially occluded sinus, and 1 patient had a stenotic draining vein.

\section{Hemorrhagic Presentation Versus Neurological Deficit}

Table 4 summarizes the main findings of the analysis comparing, between groups $2 \mathrm{a}$ and $2 \mathrm{~b}$, the frequency of variables related to restriction to drainage. The DAVF drainage sinus was normal in $32(60.1 \%)$ patients in group $2 \mathrm{a}$ and in $17(40.5 \%)$ patients in group $2 \mathrm{~b}(\mathrm{p}=0.009)$. Stenosis or occlusion of DAVF draining veins was observed in $26(55.4 \%)$ patients in group $2 \mathrm{a}$ and in $5(11.9 \%)$ patients in group $2 \mathrm{~b}(\mathrm{p}<0.001)$. A single DAVF draining vein was present in $26(55.3 \%)$ patients in group $2 \mathrm{a}$ and in $34(81.0 \%)$ patients in group $2 b(p=0.010)$. Use of the 
TABLE 5. Venous restriction variables: comparison of patients with high-grade fistulas (Cognard types 2B to 5 and Borden types 2 and 3 ) and minor symptoms versus patients with high-grade fistulas and major symptoms

\begin{tabular}{|c|c|c|c|}
\hline \multirow[b]{2}{*}{ Drainage } & \multicolumn{2}{|c|}{ High-Grade Fistula Symptoms } & \multirow[b]{2}{*}{$\begin{array}{c}p \\
\text { Value }\end{array}$} \\
\hline & $\begin{array}{c}\text { Minor } \\
\text { (group 1: } n=48 \text { ) }\end{array}$ & $\begin{array}{c}\text { Major } \\
\text { (group 2: } \mathrm{n}=80 \text { ) }\end{array}$ & \\
\hline \multicolumn{4}{|l|}{ Fistula drainage } \\
\hline $\begin{array}{l}\text { Sinus drainage } \\
\text { condition }\end{array}$ & & & 0.063 \\
\hline Normal & $25(52.1 \%)$ & $43(53.8 \%)$ & \\
\hline Stenosis & $5(10.4 \%)$ & $1(1.25 \%)$ & \\
\hline Occlusion & $18(37.5 \%)$ & $36(45.0 \%)$ & \\
\hline $\begin{array}{l}\text { No. of venous } \\
\text { drainage directions }\end{array}$ & & & 0.003 \\
\hline 1 & $4(8.33 \%)$ & $25(31.3 \%)$ & \\
\hline$\geq 2$ directions & $44(91.7 \%)$ & $55(68.8 \%)$ & \\
\hline $\begin{array}{l}\text { Cortical draining } \\
\text { veins }\end{array}$ & & & $<0.001$ \\
\hline Normal & $45(93.8 \%)$ & $50(62.5 \%)$ & \\
\hline Stenosis & $3(6.25 \%)$ & $28(35.0 \%)$ & \\
\hline Occlusion & $0(0.00 \%)$ & $2(2.50 \%)$ & \\
\hline Anastomosis type & & & 0.55 \\
\hline Good & $29(60.4 \%)$ & $44(55.0 \%)$ & \\
\hline Mixed & $13(27.1 \%)$ & $20(25.0 \%)$ & \\
\hline Tiny & $6(12.5 \%)$ & $16(20.0 \%)$ & \\
\hline \multicolumn{4}{|l|}{ Cerebral drainage } \\
\hline $\begin{array}{l}\text { Shared use of main } \\
\text { pathway }\end{array}$ & $31(64.6 \%)$ & $55(68.8 \%)$ & 0.63 \\
\hline $\begin{array}{l}\text { Absence of } \\
\text { alternative pathway }\end{array}$ & $6(12.5 \%)$ & $25(31.3 \%)$ & 0.017 \\
\hline $\begin{array}{l}\text { Presence of contrast } \\
\text { stagnation }\end{array}$ & $11(22.9 \%)$ & $39(48.8 \%)$ & 0.004 \\
\hline
\end{tabular}

Values are presented as number (\%) of patients.

main drainage pathway by the brain and the fistula was observed in $25(53.2 \%)$ patients in group $2 \mathrm{a}$ and in $34(85.0 \%)$ patients in group $2 \mathrm{~b}(\mathrm{p}=0.002)$. There was no alternative drainage route in $8(17 \%)$ patients from group $2 \mathrm{a}$ and in 18 $(45.0 \%)$ patients from group $2 \mathrm{~b}(\mathrm{p}=0.004)$. Contrast stagnation was observed in $14(29.8 \%)$ patients in group 2a and in $25(62.5 \%)$ patients in group $2 \mathrm{~b}(\mathrm{p}=0.002)$.

\section{High-Grade DAVF With Major Symptoms Versus High-Grade DAVF With Minor Symptoms}

Table 5 compares variables related to restriction to drainage in patients with high-grade fistulas (Cognard types $2 \mathrm{~B}$ to 5 and Borden types 2 and 3). In 128 patients harboring high-grade fistulas, 48 (37.5\%) had minor symptoms. The analysis of fistula drainage revealed that the sinus expected to drain the fistula was occluded in 18 (37.5\%) patients with minor symptoms and in $36(45.0 \%)$ patients with major symptoms $(\mathrm{p}=0.063)$. Multiple venous drainage directions were present in 44 (91.7\%) patients with minor symptoms and in 55 (68.8\%) patients with major symptoms $(\mathrm{p}=0.003)$. Cortical draining veins were stenotic in $3(6.25 \%)$ patients with minor symptoms and in $28(35.0 \%)$ patients with major symptoms $(\mathrm{p}<0.001)$. The anastomoses between venous territories were tiny in 6 (12.5\%) patients with minor symptoms and in 16 (20.0\%) patients with major symptoms $(\mathrm{p}=0.55)$.

The analyses of brain drainage evidenced that 31 (64.6\%) patients with minor symptoms and 55 (68.8\%) patients with major symptoms shared the main drainage pathway with the fistula $(\mathrm{p}=0.63)$. There were no alternative drainage pathways to the brain in $6(12.5 \%)$ patients with minor symptoms and in 25 (31.3\%) patients with major symptoms $(\mathrm{p}=0.017)$. Contrast stagnation was found in $11(22.9 \%)$ patients with minor symptoms and in 39 $(48.8 \%)$ patients with major symptoms $(\mathrm{p}=0.004)$.

\section{Discussion}

In this retrospective angiographic study involving patients with DAVF from three centers in two countries, comparing the venous architecture between patients presenting with major symptoms and patients with minor symptoms, a relationship was found between presentation with major symptoms and restriction in the venous drainage. Statistical significance was observed in patients with major symptoms, in whom it was more often found that the fistula drained toward the brain's main drainage pathway and there was no efficient alternative route for brain venous drainage. The presence of more frequent contrast stagnation in the brain parenchyma was also statistically significant. These findings reflect cerebral venous congestion as a result of a restriction in venous drainage. In DAVF draining veins, a higher prevalence of stenosis and tiny anastomoses in the connections between venous territories was observed in patients with major symptoms, causing restriction to DAVF drainage with consequent hemorrhage.

A comparative analysis of patients with major symptoms (hemorrhage versus severe neurological symptoms) showed a higher prevalence of stenosis in the DAVF draining veins in patients presenting with hemorrhage, suggesting that such stenosis increases the pressure on the venous side of the fistula, leading to hemorrhage. In the nonhemorrhage group, most patients exhibited shared use of the brain's main drainage pathway; there was no alternative drainage pathway to the brain; and brain parenchyma contrast stagnation was observed.

Comparison between high-grade fistulas with minor versus major symptoms was also performed, seeking to identify the variables related to a better outcome in this group of patients. It was statistically significant that highgrade fistulas with minor symptoms had more than one venous drainage direction. In this same group of patients, DAVF draining veins were rarely found to be stenotic. In the study of variables related to brain drainage restriction in patients with high-grade fistulas, we found that patients with minor symptoms had alternative pathways, allowing effective brain venous drainage in $87.5 \%$ of the cases, and had contrast stagnation in only $22.9 \%$. These findings point toward the same conclusions, namely that symptoms 
are related to the loss of competence of the venous system in providing proper drainage to the brain or to the fistula.

The evaluation of venous circulation in this group of patients with DAVF focused on the identification of the key anastomotic veins, the main cerebral venous drainage pathways, and factors that restrict venous drainage. In this study, we identified variables associated with loss of efficacy in the venous drainage of the DAVF and of the cerebral parenchyma, which ultimately is the cause of symptoms. Among the patients with major symptoms, the hemorrhage subgroup exhibited greater restriction in the DAVF draining veins, leading to increased pressure and rupture. On the other hand, nonhemorrhagic neurological symptoms (dementia, extrapyramidal syndromes, focal deficits, venous infarction, and epilepsy) are caused by an association between an overload caused by the DAVF flow and failure of the venous system to provide alternative pathways for venous brain drainage, leading to congestion.

We found that in the most recently published case series, the factors associated with restricted venous drainage have not been examined in depth. In reviewing their series of 85 patients, Söderman et al. ${ }^{21}$ described venous drainage using the Borden and Cognard classifications, without further details on brain venous anatomy. The authors concluded that the risk of hemorrhage was lower than previously estimated and identified presentation with hemorrhage as the most significant predictor of future hemorrhagic events.

In a review of 300 patients, Geibprasert et al. ${ }^{30}$ proposed a new classification of dural arteriovenous shunts based on embryology. The lesions were classified accordingly to their location into ventral epidural, dorsal epidural, and lateral epidural. Restriction to venous drainage should be analyzed in those three groups by identifying stenosis or occlusion of draining veins, which could be proximal or distal to the shunt, or both. The authors sought to correlate restriction of the venous drainage with the development of cortical venous reflux. According to that classification, lateral epidural lesions would be the most aggressive.

Strom et al. ${ }^{31}$ reviewed 28 patients with Borden type 2 and 3 fistulas and divided them into two groups, those considered symptomatic with hemorrhage or progressive neurological deficit and those considered asymptomatic. Their findings showed clinical deterioration in $45.5 \%$ of symptomatic patients versus $5.9 \%$ in patients considered asymptomatic. The authors concluded that fistulas with cortical venous reflux that do not present with hemorrhage or progressive neurological deficit in the initial diagnosis have a more benign course than those with these findings. The authors suggested that patients with asymptomatic cortical venous reflux may not have severe venous hypertension, which may be due to lower blood flow through the fistula, a more efficient collateral system, or other factors at the microvascular level.

Baltsavias and Valavanis ${ }^{32}$ use the Borden and Cognard classifications, as well as the classification proposed by Geibprasert et al., ${ }^{30}$ in describing venous drainage in their series of 170 patients. Their article focuses on treatment results, and the authors refer to other published studies with regard to the correlation between symptoms and venous drainage. In their conclusion, Baltsavias and Vala- vanis draw attention to the fact that a poor understanding of the angioarchitecture in DAVF patients may lead to excessive treatment in benign lesions.

In this retrospective analysis of 201 patients with DAVF, a complete venous drainage study was performed to identify whether patient venous anatomy would influence the development of symptoms. Beyond DAVF draining veins, brain anastomotic veins and brain draining pathways were identified in order to recognize conditions associated with restriction to fistula drainage, as well to brain venous drainage. Other authors have identified and described this association. ${ }^{17,20,30,31,33-44}$ DAVF and cerebral circulations were overlapped to verify whether the fistula used the brain's main drainage direction, and whether the brain had an effective alternative drainage route uncontaminated by blood from the shunt.

The demographic and clinical characteristics of our study population are similar to those reported in previously published case series..$^{13,14,17-19,27,31}$ Group 2 had a statistically significant predominance of males and a high number of patients harboring Borden type 3 and Cognard type 3 and 4 lesions. The angiographic findings commonly described in the literature as being associated with major symptoms are also reflected in our study population. Cortical venous drainage, venous ectasia, and pseudophlebitis patterns correlated positively with major symptoms.

In patients with major symptoms and neurological manifestations (group 2b), there was an association between severe cortical reflux and restriction to brain venous drainage caused by competition between the fistula and the brain for use of the main drainage pathway, leading to a greater frequency of contrast stagnation in that group. In $45 \%$ of group $2 \mathrm{~b}$ patients, there were no alternative pathways for cerebral venous drainage, while in group $2 \mathrm{a}$, this was found in only $17 \%$ of the cases. The restriction to the cerebral venous drainage, caused by the absence of alternative drainage pathways, led to the development of neurological symptoms not related to hemorrhage in group $2 b$. The status of the draining veins, in particular the presence of stenosis, was the most important determining factor for hemorrhage. This was found in $51.1 \%$ of patients in group 2a, compared with $11.9 \%$ in group $2 \mathrm{~b}$ (Table 4 ).

The absence of a particular venous element does not influence the clinical presentation (Table 2). The most important treatment goal is to determine if there is a restriction to the brain or fistula venous drainage. The comparison between patients with high-grade fistulas and minor symptoms versus those with high-grade fistulas and major symptoms also points to this direction. The group of high-grade lesions with minor symptoms had significantly fewer elements restricting the venous circulation, thus indicating that, in some instances, high-grade lesions do not develop major symptoms because of an efficient draining system (Table 5).

This study was not intended to replace the current DAVF classification systems; rather, its importance to clinical practice is in the possibility of using additional objective elements that increase the understanding of fistulas, particularly with regard to daily therapeutic decisions. Söderman et al. ${ }^{21}$ and Strom et al. ${ }^{31}$ concluded that patients with high-grade fistulas who do not present with 
hemorrhage are less likely to bleed. In such patients, the identification of venous collectors suitable for drainage of the fistula and brain tissue allows greater assurance when opting for a conservative treatment.

The main limitation of this study is the retrospective and cross-sectional design, which does not provide information on long-term clinical outcomes to support the hypotheses. The exclusion of patients with multiple DAVFs is another limitation, although multiple DAVFs were found in few patients. The DAVF low incidence rate, associated with a significant variety of phenotypes, makes statistical analysis a challenging task.

This study aimed to globally evaluate the venous system in patients with DAVF, from venous territories to the final venous drainage pathways, with the aim of investigating the hypothesis that clinical symptoms occur when there is failure to provide adequate drainage to the brain or the fistula. Therefore, in addition to the venous drainage of the DAVF, it is important to systematically evaluate the cerebral venous system in order to understand the clinical phenomena exhibited by patients with DAVF.

DAVF is a complex and challenging disease in neurosurgical practice. Its wide range of phenotypes, from benign conditions to aggressive life-threatening situations, its interactions with the brain venous drainage, and the complexity of its radioanatomy make DAVF analyses a process of learning of brain venous functional anatomy. It is important to systematize the evaluation of venous circulation in these patients, using a methodology that allows for a comprehensive assessment of the impact of DAVF on cerebral circulation. The main contribution of this study is a proposal for analysis based not only on DAVF drainage, but also on the anastomotic veins and brain final drainage pathways.

\section{Conclusions}

This study highlights the importance of going beyond using the consolidated classifications and directing the study of the venous system of patients with DAVF toward the identification of the factors that restrict drainage of the fistula as well as of the brain. Inability of the venous system to provide adequate blood circulation to the fistula and to the brain tissue is the ultimate factor in the development of symptoms.

The finding most closely associated with restriction of venous drainage was the presence of stenosis in the DAVF draining veins. The restriction of brain venous circulation was positively associated with the use of the main cerebral drainage pathway by the DAVF, with the lack of an alternative route for cerebral venous drainage, and with the presence of contrast stagnation in the brain parenchyma.

\section{References}

1. Terada T, Higashida RT, Halbach VV, et al. Development of acquired arteriovenous fistulas in rats due to venous hypertension. J Neurosurg. 1994;80(5):884-889.

2. Lawton MT, Jacobowitz R, Spetzler RF. Redefined role of angiogenesis in the pathogenesis of dural arteriovenous malformations. J Neurosurg. 1997;87(2):267-274.

3. Li Q, Zhang Q, Huang QH, et al. A pivotal role of the vascular endothelial growth factor signaling pathway in the for- mation of venous hypertension-induced dural arteriovenous fistulas. Mol Med Rep. 2014;9(5):1551-1558.

4. Warren DJ, Craven I, Romanowski CAJ, Coley SC. Spontaneous closure of a type 2 a dural arteriovenous fistula following late recanalization of the occluded sinus. Interv Neuroradiol. 2010;16(3):282-285.

5. Chen L, Mao Y, Zhou LF. Local chronic hypoperfusion secondary to sinus high pressure seems to be mainly responsible for the formation of intracranial dural arteriovenous fistula. Neurosurgery. 2009;64(5):973-983.

6. Wang SS, Li CH, Zhang XJ, Wang RM. Investigation of the mechanism of dural arteriovenous fistula formation induced by high intracranial venous pressure in a rabbit model. $B M C$ Neurosci. 2014;15:101.

7. Miller TR, Gandhi D. Intracranial dural arteriovenous fistulae: clinical presentation and management strategies. Stroke. 2015;46(7):2017-2025.

8. Orina JN, Daniels DJ, Lanzino G. Familial intracranial dural arteriovenous fistulas. Neurosurgery. 2013;72(2):E310-E313.

9. Matsubara S, Satoh K, Satomi J, et al. Acquired pial and dural arteriovenous fistulae following superior sagittal sinus thrombosis in patients with protein S deficiency: a report of two cases. Neurol Med Chir (Tokyo). 2014;54(3):245-252.

10. van Dijk JMC, TerBrugge KG, Van der Meer FJ, et al. Thrombophilic factors and the formation of dural arteriovenous fistulas. J Neurosurg. 2007;107(1):56-59.

11. Borden JA, Wu JK, Shucart WA. A proposed classification for spinal and cranial dural arteriovenous fistulous malformations and implications for treatment. J Neurosurg. 1995;82(2): 166-179.

12. Cognard C, Gobin YP, Pierot L, et al. Cerebral dural arteriovenous fistulas: clinical and angiographic correlation with a revised classification of venous drainage. Radiology. 1995; 194(3):671-680.

13. Hiramatsu M, Sugiu K, Hishikawa T, et al. Epidemiology of dural arteriovenous fistula in Japan: analysis of Japanese registry of neuroendovascular therapy (JR-NET2). Neurol Med Chir (Tokyo). 2014;54(1):63-71.

14. Li C, Wang Y, Li Y, et al. Clinical and angioarchitectural risk factors associated with intracranial hemorrhage in dural arteriovenous fistulas: a single-center retrospective study. $P L O S$ One. 2015;10(6):e0131235.

15. Hetts SW, Tsai T, Cooke DL, et al. Progressive versus nonprogressive intracranial dural arteriovenous fistulas: characteristics and outcomes. AJNR Am J Neuroradiol. 2015;36(10): 1912-1919.

16. Willinsky R, Terbrugge K, Montanera W, et al. Venous congestion: an MR finding in dural arteriovenous malformations with cortical venous drainage. AJNR Am J Neuroradiol. 1994;15(8):1501-1507.

17. Willinsky R, Goyal M, terBrugge K, Montanera W. Tortuous, engorged pial veins in intracranial dural arteriovenous fistulas: correlations with presentation, location, and MR findings in 122 patients. AJNR Am J Neuroradiol. 1999;20(6): 1031-1036.

18. Shin NY, Kwon YS, Ha SY, et al. Venous angioarchitectural features of intracranial dural arteriovenous shunt and its relation to the clinical course. Neuroradiology. 2013;55(9): 1119-1127.

19. Singh V, Smith WS, Lawton MT, et al. Risk factors for hemorrhagic presentation in patients with dural arteriovenous fistulae. Neurosurgery. 2008;62(3):628-635.

20. Miyamoto N, Naito I, Takatama S, et al. Clinical and angiographic characteristics of cavernous sinus dural arteriovenous fistulas manifesting as venous infarction and/or intracranial hemorrhage. Neuroradiology. 2009;51(1):53-60.

21. Söderman M, Pavic L, Edner G, et al. Natural history of dural arteriovenous shunts. Stroke. 2008;39(6):1735-1739.

22. Zipfel GJ, Shah MN, Refai D, et al. Cranial dural arterio- 
venous fistulas: modification of angiographic classification scales based on new natural history data. Neurosurg Focus. 2009;26(5):E14.

23. Davies MA, Saleh J, Ter Brugge K, et al. The natural history and management of intracranial dural arteriovenous fistulae. Part 1: benign lesions. Interv Neuroradiol. 1997;3(4): 295-302.

24. Satomi J, van Dijk JM, Terbrugge KG, et al. Benign cranial dural arteriovenous fistulas: outcome of conservative management based on the natural history of the lesion. J Neurosurg. 2002;97(4):767-770.

25. Kim DJ, terBrugge K, Krings T, et al. Spontaneous angiographic conversion of intracranial dural arteriovenous shunt: long-term follow-up in nontreated patients. Stroke. 2010; 41(7):1489-1494.

26. Davies MA, Ter Brugge K, Willinsky R, Wallace MC. The natural history and management of intracranial dural arteriovenous fistulae. Part 2: aggressive lesions. Interv Neuroradiol. 1997;3(4):303-311.

27. van Dijk JMC, terBrugge KG, Willinsky RA, Wallace MC. Clinical course of cranial dural arteriovenous fistulas with long-term persistent cortical venous reflux. Stroke. 2002; 33(5):1233-1236.

28. Pop R, Manisor M, Aloraini Z, et al. Foramen magnum dural arteriovenous fistula presenting with epilepsy. Interv Neuroradiol. 2015;21(6):724-727.

29. Santos AF, Machado C, Varanda S, et al. Encephalopathy resulting from dural arteriovenous fistula. Perm J. 2016;20(3): $15-218$

30. Geibprasert S, Pereira V, Krings T, et al. Dural arteriovenous shunts: a new classification of craniospinal epidural venous anatomical bases and clinical correlations. Stroke. 2008; 39(10):2783-2794.

31. Strom RG, Botros JA, Refai D, et al. Cranial dural arteriovenous fistulae: asymptomatic cortical venous drainage portends less aggressive clinical course. Neurosurgery. 2009; 64(2):241-248.

32. Baltsavias G, Valavanis A. Endovascular treatment of 170 consecutive cranial dural arteriovenous fistulae: results and complications. Neurosurg Rev. 2014;37(1):63-71.

33. Lasjaunias P, Chiu M, ter Brugge K, et al. Neurological manifestations of intracranial dural arteriovenous malformations. J Neurosurg. 1986;64(5):724-730.

34. Ishii K, Goto K, Ihara K, et al. High-risk dural arteriovenous fistulae of the transverse and sigmoid sinuses. AJNR Am J Neuroradiol. 1987;8(6):1113-1120.

35. Lalwani AK, Dowd CF, Halbach VV. Grading venous restrictive disease in patients with dural arteriovenous fistulas of the transverse/sigmoid sinus. J Neurosurg. 1993;79(1):11-15.

36. Cognard C, Casasco A, Toevi M, et al. Dural arteriovenous fistulas as a cause of intracranial hypertension due to impairment of cranial venous outflow. J Neurol Neurosurg Psychiatry. 1998;65(3):308-316.
37. Tsai LK, Jeng JS, Liu HM, et al. Intracranial dural arteriovenous fistulas with or without cerebral sinus thrombosis: analysis of 69 patients. J Neurol Neurosurg Psychiatry. 2004; 75(11):1639-1641.

38. Dabus G, Bernstein RA, Hurley MC, et al. Reversal of diffusion restriction after embolization of dural arteriovenous fistula: case report. Neurosurgery. 2010;67(4):E1147-E1151.

39. Uchiyama T, Horiuchi T, Murata T, Hongo K. Dural arteriovenous fistula between inferolateral trunk of the internal carotid artery and superficial sylvian vein. Neurol Med Chir (Tokyo). 2011;51(9):642-644.

40. Gross BA, Du R. The natural history of cerebral dural arteriovenous fistulae. Neurosurgery. 2012;71(3):594-603.

41. Oh JT, Chung SY, Lanzino G, et al. Intracranial dural arteriovenous fistulas: clinical characteristics and management based on location and hemodynamics. J Cerebrovasc Endovasc Neurosurg. 2012;14(3):192-202.

42. Labeyrie MA, Lenck S, Saint-Maurice JP, et al. Dural arteriovenous fistulas presenting with reversible dementia are associated with a specific venous drainage. Eur J Neurol. 2014; 21(3):545-547.

43. Fujii H, Nagano Y, Hosomi N, Matsumoto M. Dural arteriovenous fistula presenting with progressive dementia and parkinsonism. BMJ Case Rep. 2014;2014:bcr2014203921.

44. Gross R, Ali R, Kole M, et al. Tentorial dural arteriovenous fistula presenting as myelopathy: case series and review of literature. World J Clin Cases. 2014;2(12):907-911.

\section{Disclosures}

The authors report no conflict of interest concerning the materials or methods used in this study or the findings specified in this paper.

\section{Author Contributions}

Conception and design: Melo Neto, Bracard, Oliveira. Acquisition of data: Melo Neto, Pelinca da Costa, Pinheiro Junior, Rodesch, Bracard. Analysis and interpretation of data: Melo Neto, Pelinca da Costa, Pinheiro Junior, Rodesch, Oliveira. Drafting the article: Melo Neto, Oliveira. Critically revising the article: Batista, Bracard, Oliveira. Reviewed submitted version of manuscript: Melo Neto, Pelinca da Costa, Pinheiro Junior, Batista, Bracard, Oliveira. Approved the final version of the manuscript on behalf of all authors: Melo Neto. Statistical analysis: Oliveira. Administrative/technical/material support: Melo Neto, Bracard, Oliveira. Study supervision: Oliveira.

\section{Correspondence}

João Ferreira de Melo Neto: Hospital Universitário Onofre Lopes, Universidade Federal do Rio Grande do Norte, Natal/RN, Brazil. jfmeloneto72@gmail.com. 